\title{
An Overview of Users Information Seeking Behaviour on Online Resources
}

\author{
Esew, Michael ${ }^{1}$, Aisha Makarfi ${ }^{2}$, Rhoda Wusa Goshie $^{3}$, Aisha Jimada ${ }^{4}$

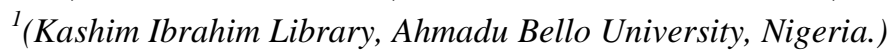 \\ ${ }^{2}$ (Federal College Of Education Library Zaria, Nigeria.) \\ ${ }^{3}$ (Kashim Ibrahim Library, Ahmadu Bello University, Nigeria.) \\ ${ }^{4}$ (Kashim Ibrahim Library, Ahmadu Bello University, Nigeria.)
}

\begin{abstract}
This paper discuses online information seeking behavior of students for sustainable education among students of higher learning institutions. Online information seeking behavior is a relatively new phenomenon. However, it is the active process of obtaining data from the Web. Libraries and Universities are continuously adapting and seeking effective ways to respond to the fundamental and interconnected missions of research, teaching and community service, and that is why some have embraced the use of the Internet in service delivery. On the other hand, this study is more concerned with maximizing usage of this resource by students in fulfilling their primary aim of research and reaching out to these resources on the Internet using the requisite navigational skills. The paper says the Internet offers widespread access to electronic resources and also has the advantages of interactivity, and information tailoring. It also agrees that access is inequitable and use is hindered by navigational challenges due to numerous factors e.g. disorganization, technical language and lack of permanence. Meager information evaluation skills add to students' vulnerability. The paper highlights some information seeking models to assist students in their search for information on the Internet. Also it highlights the role of the library in the information seeking process of students. The paper concludes that though Information and communication technologies are being put in place for use by students, they must possess the requisite skill to use them appropriately.
\end{abstract}

Keywords: Information, Information need, Information Seeking Behavior, Online Information seeking, Online information seeking theories.

\section{Introduction}

The dawn of the internet era has changed the way information is created, distributed and consumed, with a visible impact on the global system of communication. With the advent of new technologies like tablets and ebooks, there has been a discernible shift in how users consume information. Information is defined by Reitz (2004) as all conclusions, ideas and creative works of the human intellect and imagination that have been communicated formally and informally in any form. In a similar definition, Aina (2008) defines information as meaningful communication symbols transferred between any two points in human communication or machine networks. Information therefore can be seen as anything that causes some behavioural changes when assimilated by an individual. Aguolu (1984) asserts that information can increase our awareness and help us educate our people, accelerate progress and provide the source data required for the solution to our increasingly complex economic, social and scientific problems.

The concept of information has been defined in many different ways. In the cognitive view point of information science, Belkin (2007) defines: the information associated with a text is the generator's modified (by purpose, intent, knowledge of the recipient state of knowledge) conceptual structure which underlines the surface structure (e.g. language of that text). This definition of information is subsequently elaborated by Ingwersen (2008) as being the result of a transformation of the generator's cognitive structure (by intentionality, model of the recipients' state of knowledge and in the form of signs). On the other hand, it is a structure, which when perceived, may affect and transform the recipient's state of knowledge. In this study therefore, information is conceptualized as something which students need during their studies when they construct meaning to the subject in the process of learning.

\section{Relevance Of Online Information To Academics}

The importance of information in an academic environment cannot be overemphasized. Better still online information resources as asserted by Gbaje (2007) facilitate access to relevant and current information for teaching, learning and research development. Academics in any society are seen as propellers of knowledge.

Higher education is changing rapidly with the advent of technology. According to Shuling (2007), these days, electronic information resources have gradually become imperative in every university library. Majid et al (1999) argue that technological advancements have opened up new horizons for the creation, storage, access, distribution 
and presentation of information. Brophy

(1993) noted that the advantages of electronic information resources over print ones include the following, speed, ease of use, ability to search multiple files at the same time, ability to save, print and repeat searches, frequent updating and the ability to access from outside the library (more advantageous to distant learners).

Academics now live in a seemingly new world because using the Internet to support learning and teaching is growing exponentially, as more educational organisations are recognizing the potential that it offers. The rapid advancement of Information and Communication Technology (ICT) has brought a revolutionary change in the information scenario, giving rise to a number of options to the users' community, to handle varied information sources conveniently and effortlessly Swain and Parda (2009).

Similarly, Dadzie (2005) further highlights the importance of online information to academics, stating that online information could be accessed by users that are restricted by geographical location or finances, access to current information and provision of extensive links to additional resources or related content. They could be stored electronically, thereby saving space, avoiding the risk of loss, lessening theft or damage and cost is significantly reduced.

\section{Information Behaviour}

Information behaviour encompasses information seeking as well as the totality of other unintentional or passive behaviours (such as glimpsing or encountering information), and purposive behaviours that do not involve seeking,: such as avoiding information Case, (2002). Based on the general model of information behaviour developed by Wilson (1997), he posited that a general model of information behaviour needs to include at least three elements:

i. An information need and its drives, i.e. the factors that give rise to an individual's perception of need,

ii. The factors that affect the individual's response to the perception of needs; and,

iii. The processes or actions involved in that response.

Taylor (1991) asserted that information is the product of certain elements of the information use environment. These elements according to him are: the assumptions, formerly or informally learned, made by a defined set of people concerning their nature of work, the kind and structure of the problems deemed difficult and typical of this set of people, the constraints and opportunities of typical environments within which any group or sub-group of this set of people operate and work, and the conscious or perhaps unconscious assumptions made as to what constitutes a solution or better said a resolution of problems and what makes information useful and valuable in their contexts. From the above therefore, information behaviour can be said to be the totality of human behaviour in relation to sources and channels of information, including both active and passive information seeking and use.

\section{Information Seeking}

With the proliferation of online information resources on the Web, information seeking in this environment is pertinent. Case (2002) succinctly says that information seeking is a conscious effort to acquire information in response to a need or gap in the knowledge of a client. Ikoja-Odongo and Ochalla (2004) described information seeking as a process that requires an information seeker's cognitive ability, his or her knowledge and skills regarding information seeking. Taylor and Procter (2005) define information seeking more simply, stating that it is the ability to scan literature efficiently using manual or computerized method to identify a set of useful articles and books. Information seeking therefore is that process by which an information seeker undergoes in search for a suitable information to satisfy a desired information need.

\section{Information Need}

Information need is defined as that need originating from a vague awareness of something missing and then culminating in locating information that contributes to understanding and meaning Kuhlthau (1993). It is an anomalous state of knowledge Belkin, Brooks and Oddy (1982) or a gap in an individual's knowledge in sense making situations Devin \& Nilan (1986). For a person to experience an information need, there must be a motive behind it, Wilson (1997). From the above definitions therefore, it can be noted that an information need is recognition that one's knowledge is inadequate to satisfy a goal that is at hand.

\section{Information Seeking Behaviour}

Information-seeking behaviour begins when one realizes the existence of an information need and ends when that need is believed to have been satisfied Krikelas (1983). The seeker turns to formal and informal sources of information and is ultimately satisfied or dissatisfied with the end result Wilson (2009). Similarly, it can be defined as an individual's way and manner of gathering and sourcing for information for personal use, knowledge updating and development. A lot of it is intangible and takes place in a person's head, making it 
difficult to measure. Faire-Wessels (1990) in Kakai et al (2004) refers to it as a way people search for and utilized information. From the above definitions therefore, it can be deduced that information seeking behaviour is the purposive search for information as a consequence of a need to satisfy some goals. In the course of seeking for information to do research and assignments, the individual may interact with manual information systems (such as newspaper or a book) or with computer-based systems (such as the Internet-world wide web).

\section{Online Information Seeking}

Online information seeking behaviour is the active process of obtaining data from the Internet. This definition arises from the perception that any activity an individual engages in on the Internet constitutes information seeking. The study stresses that the choices users make when searching i.e. - what terms they choose, how many, and other features (e.g. phrase search or Boolean logic) they naturally select - are key areas of research in the online environment. Information Seeking Theories

Information seeking is the process of or activity of attempting to obtain information in both human and technological contexts. A variety of theories of information behaviour e.g. Zipf s Principle of Least Effort, Brenda Dervin's Sense, Making and Elfreda Chatman's Life in the Rounds, seek to understand the processes that surround information seeking. Foster (2005); Kuhlthau (2006), assert that information seeking has generally been accepted as dynamic and non-linear. People experience the information search as a process of interplay of thoughts, feelings and actions Kuhlthau (2006).

Taylor's Question-Negotiation and Information Seeking Model

Taylor described four levels of information need as:

Q1 - the actual, but unexpressed need for information (the visceral need) Q2 - the conscious, with-in brain description of the need (the conscious need) Q3 - the formal statement of the need (the formalized need) Q4 - the question as presented to the information system (the compromised need) (Question Negotiation and Information Seeking)

The visceral level $(\mathrm{Ql})$ is the initial need for information that a user has. This need will change as information is added. At the conscious level (Q2) the user has an ambiguous mental description of what it is that he or she is looking for, but may need a colleague to help him/her focus the topic. At this stage the user has a conscious description of the process. At the formal level (Q3), the user may question whether or not the information system can answer their question and the user may or may not realize that the librarian is a part of the information system. The compromised level (Q4) is the level at which the question is formalized. This is the stage at which the user may contact the reference librarian or take into account the organization of the files of information the library posses (books, pamphlets, tables, etc.) The reference librarian may have to go back to earlier stages in order to obtain information from the process that will help attain the answer to the inquiry.

\section{Dervin's Sense Making Metaphor}

Dervin's sense-making theory has developed over a number of years, and cannot be seen simply as a model of information-seeking behaviour: it is, rather, as she says '... a set of assumptions, a theoretic perspective, a methodological approach, a set of research methods, and a practice.' designed to cope with information perceived as, '... a human tool designed for making sense of a reality assumed to be both chaotic and orderly.' However, sense-making is implemented in terms of four constituent elements - a situation in time and space, which defines the context in which information problems arise; a gap, which identifies the difference between the contextual situation and the desired situation (e.g. uncertainty); an outcome, that is, the consequences of the sense-making process, and a bridge, that is, some means of closing the gap between situation and outcome. Dervin presents these elements in terms of a triangle: situation, gap/bridge, and outcome, which can be seen in the figure below:

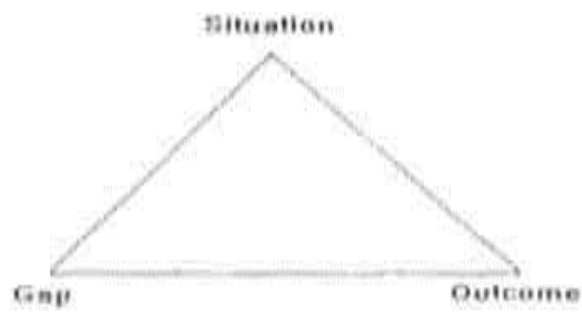

Figure 1: Dervin's 'sense-making' triangle.

However, it may be preferable to use the bridge metaphor more directly and present the model as in figure 4 below: 


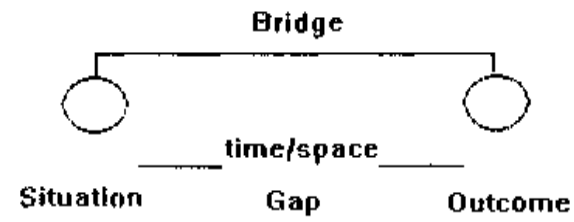

Figure 2: Dervin's 'sense-making' model re-drawn

The strength of Dervin's model lies partly in its methodological consequences, since, in relation

to information behaviour, it can lead to a way of questioning that can reveal the nature of a problematic situation, the extent to which information serves to bridge the gap of uncertainty, confusion, or whatever, and the nature of the outcomes from the use of information. Applied consistently in 'micro-moment, time-line interviews' such questioning leads to genuine insights that can influence information service design and delivery.

\section{Wilson's Information Seeking Behaviour Model}

Wilson's 1996 model is a major revision of that of 1981, drawing upon research from a variety of fields other than information science, including decision-making, psychology, innovation, health communication, and consumer research. The basic framework of the 1981 model persists, in that the person in context remains the focus of information needs, the barriers are represented by intervening variables and information-seeking behaviour is identified. However, there are also changes: the use of the term intervening variables serves to suggest that their impact may be supportive of information use as well as preventive; information-seeking behaviour is shown to consist of more types than previously, where the active search was the focus of attention; information processing and use is shown to be a necessary part of the feedback loop, if information needs are to be satisfied; and three relevant theoretical ideas are presented: stress/coping theory, which offers possibilities for explaining why some needs do not invoke information-seeking behaviour; risk/reward theory, which may help to explain which sources of information may be used more than others by a given individual; and social learning theory, which embodies the concept of self-efficacy, the idea of'the conviction that one can successfully execute the behavior required to produce the desired outcomes'.

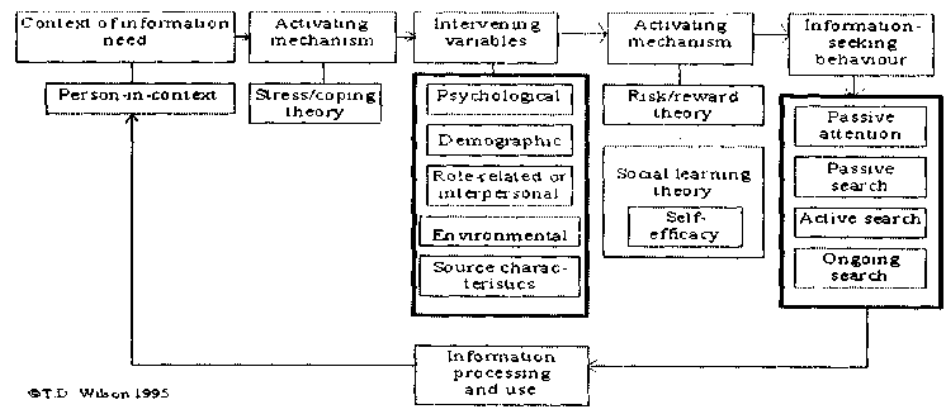

Figure 3: Wilson's model of 1996

Thus, the model remains one of macro-behaviour, but its expansion and the inclusion of other theoretical models of behaviour makes it a richer source of hypotheses and further research than Wilson's earlier model.

\section{Ellis' Model Of Information Seeking Behaviour}

Ellis (1989), Ellis et al (1993) and Ellis and Haugan (1997), proposed and elaborated a general

model of information seeking behaviour based on studies of the information seeking patterns of academics. The model describes six categories of information seeking activities as generic: starting, chaining, browsing, differentiating, monitoring and extracting.

Starting: This comprises those activities that form the initial search for information. Identifying sources of interest that could serve as starting point of the search. Identified sources often include familiar sources that have been used before as well as less familiar sources that are expected to provide relevant information to users.

Chaining: This can be either backward or forward. Backward chaining takes place when printers or references from an initial source are followed. However reversely, forward chaining identifies and follows up other sources that refer to an initial source or document. Although it can be an effective way of broadening a search, forward chaining is much less in use because people are unaware of it. 
Browsing: This is the activity of semi-directed search in areas of potential search. The individual often simplifies browsing by looking through tables of contents, lists of titles, subject headings, abstracts, and summaries and so on. Browsing takes place in many situations in which related information have been grouped together according to subject affinity. Chang and Rice (1993) define browsing as "the process of exposing oneself to a resource space by scanning its content (objects or representations), structure, possibly resulting in awareness of unexpected or new content paths in that resource space." They further regard browsing as a "rich and fundamental human information behaviour" that could lead to outcomes such as unanticipated findings, modification of information needs, learning and so on.

Differentiating: During this process, the individual filters and selects from among the sources scanned by noticing differences between the nature and quality of the information offered. This process is likely to depend on the individual's prior or initial experiences with the sources, i.e word-of-mouth, recommendations from personal contacts, or reviews in published sources. Taylor (1986) points out that for information to be relevant and consequential, it should address not only the subject matter of the problem but also the particular circumstances that affect the resolution of that problem. He identifies six categories of criteria by which individuals select and differentiate between sources: ease of use, noise reduction, quality, adaptability, time saving and cost saving.

Monitoring: This is the activity of keeping abreast of developments in an area by regularly following particular sources. The individual monitors by concentrating on a small number of what are perceived to be core sources. Core sources here include the following: journals, online search updates, newspapers, conferences, magazines, books, catalogs and so on.

Extracting: This involves systematically working through a particular source or sources in order to identify materials of interest. Taking the form of retrospective searching, extracting may be achieved by directly consulting the source, or by indirectly looking through bibliographies; indexes or online databases. Retrospective searching though, tends to be labour intensive, is more likely when there is a need for comprehensive or historical information on a topic. From the foregoing therefore, the identification of categories of information seeking behaviour also suggests that information retrieval systems could increase their usefulness by including features that directly support these activities. Ellis posited that hypertext-based systems would have the capabilities to implement these functions Ellis (1989). Relating online information as a hyperlinked information system distributed over numerous networks, most of the information seeking behaviour categories in Ellis' model are already being supported by capabilities available in common web browser software. An individual could begin surfing the web, from one of a few, favourite starting pages or sites (starting) follow hypertextual links to related information sources, both in backward and forward linking directions (chaining); scan the web pages of the sources selected (browsing); book mark useful sources for future reference and visits (differentiating; subscribe to e-mail based services that alert the use of new information or developments (monitoring) also search a particular source or site for all information on that site on a particular topic (extracting). Therefore the figure below shows comparison between the original formulations of Ellis and Extensions of the activities to web information seeking.

\begin{tabular}{|c|c|c|c|c|c|c|}
\hline $\begin{array}{l}\text { Information } \\
\text { Seeking } \\
\text { Behaviours } \\
\text { (Ellis and } \\
\text { Ellis et al } \\
1989.1993 . \\
1997 \text { ) }\end{array}$ & Starting & Chaining & Browsing & Differentiating & Monitoring & Extracting \\
\hline $\begin{array}{l}\text { Literature } \\
\text { search } \\
\text { moves }\end{array}$ & $\begin{array}{l}\text { Identification } \\
\text { of sources of } \\
\text { interest }\end{array}$ & $\begin{array}{l}\text { Following } \\
\text { up } \\
\text { references } \\
\text { found in } \\
\text { given } \\
\text { material }\end{array}$ & $\begin{array}{l}\text { Scanning } \\
\text { tables of } \\
\text { contents } \\
\text { or } \\
\text { headings }\end{array}$ & $\begin{array}{l}\text { Assessing or } \\
\text { restricting } \\
\text { information } \\
\text { according to their } \\
\text { usefulness }\end{array}$ & $\begin{array}{l}\text { Receiving } \\
\text { regular } \\
\text { reports or } \\
\text { summaries } \\
\text { from } \\
\text { selected } \\
\text { sources. }\end{array}$ & $\begin{array}{l}\text { Systematically } \\
\text { working } \\
\text { through a } \\
\text { source to } \\
\text { identify } \\
\text { material of } \\
\text { interest. }\end{array}$ \\
\hline $\begin{array}{l}\text { Anticipated } \\
\text { web moves }\end{array}$ & $\begin{array}{l}\text { Identifying } \\
\text { website } \\
\text { pages } \\
\text { containing or } \\
\text { pointing to } \\
\text { information } \\
\text { of interest }\end{array}$ & $\begin{array}{l}\text { Following } \\
\text { links on } \\
\text { starting } \\
\text { pages to } \\
\text { other } \\
\text { content } \\
\text { related } \\
\text { sites. }\end{array}$ & $\begin{array}{l}\text { Scanning } \\
\text { top level } \\
\text { pages } \\
\text { lists, } \\
\text { headings } \\
\text { site } \\
\text { maps. }\end{array}$ & $\begin{array}{l}\text { Selecting useful } \\
\text { pages and sites } \\
\text { by bookmarking, } \\
\text { printing, copying } \\
\text { and pasting etc. } \\
\text { Choosing/starting } \\
\text { at differentiated, } \\
\text { preselected site } \\
\text { of known content }\end{array}$ & $\begin{array}{l}\text { Receiving } \\
\text { site updates } \\
\text { using e.g. } \\
\text { push. agents } \\
\text { or profiles. } \\
\text { Revisiting } \\
\text { favourite } \\
\text { sites for } \\
\text { new } \\
\text { information. }\end{array}$ & $\begin{array}{l}\text { Systematically } \\
\text { searches a } \\
\text { local site to } \\
\text { extract } \\
\text { information of } \\
\text { interest at that } \\
\text { site. }\end{array}$ \\
\hline
\end{tabular}

Fig4. Literature Search Moves: Ellis Model of Information Seeking Behaviour. 


\section{Kuhlthau's Model Of The Information Search Process (Isp)}

The model of the ISP describes users' experience in the process of information seeking as a series of thoughts, feelings, and actions. Thoughts that begin as uncertain, vague, and ambiguous become clearer, more focused, and specific as the search process progresses. Feelings of anxiety and doubt become more confident and certain. Through their actions, people seek information relevant to the general topic in the beginning stages of the search process and pertinent to the focused topic toward closure. Formulation of a focus or a personal perspective of the topic is a pivotal point in the search process. At that point, feelings shift from uncertain to confident, thoughts change from vague to clear and interest increases. The model was verified in longitudinal case studies and large scale studies of diverse samples of library users. Further studies have examined the implementation of a process approach in education context and investigated the ISP in the workplace.

The ISP describes common experiences in the process of information seeking for a complex taskthat has a discrete beginning and ending and that requires considerable construction and learning to be accomplished. The model reveals a search process in which a person is seeking meaning in the course of seeking information. From the user's perspective the primary objective of information seeking is to accomplish the task that initiated the search, not merely the collection of information as an end in itself. The ISP presents seeking information as a means to accomplish a goal. The model of the ISP is articulated in a holistic view of information seeking from the user's perspective in six stages:

Initiation: When a person first becomes aware of a lack of knowledge or understanding he/she experiences a feeling of uncertainty and anxiety.

Selection: When a general area, topic, or problem is identified and initial uncertainty often gives way to a brief sense of optimism and a readiness to begin the search.

Exploration: When inconsistent, incompatible information is encountered and uncertainty, confusion, and doubt frequently increase and people find themselves "in the dip" of confidence.

Formulation: When a focused perspective is formed and uncertainty diminishes as confidence begins to increase.

Collection: When information pertinent to the focused perspective is gathered and uncertainty subsides as interest and involvement deepen.

Presentation: When the search is completed with a new understanding enabling the person to explain his or her learning to others or in someway put the learning to use.

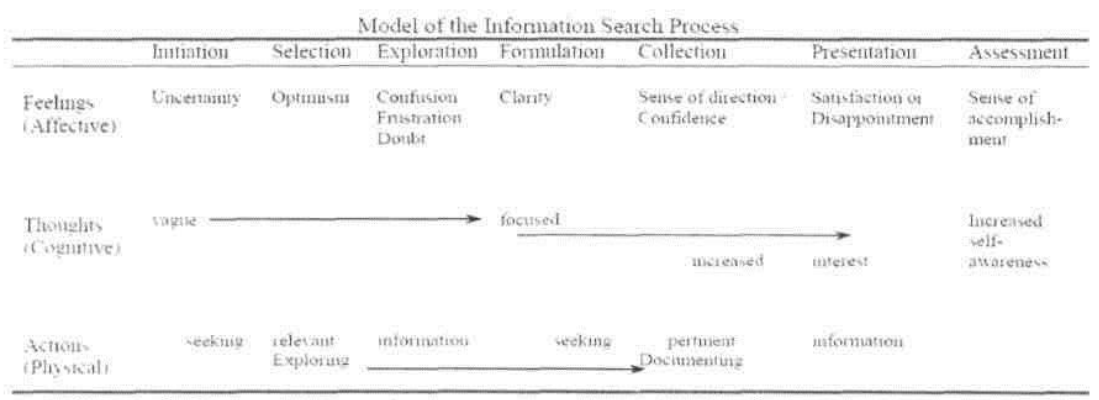

Fig 5: Kuhlthau's Model of the Information Search Process (ISP).

VI. Online Information Systems, Resources And Services

Free Dictionary (2012) defines information systems as a set of inter-related components workingtogether to collect, retrieve, process, store and distribute information over a network. It also „, consists of the networking of all communication channels used within an organisation. Online information systems occupy the centre stage of information seeking in the online environment. Online information resources initiative as maintained by Gbaje (2007) are relevant information and communication technology policies that aid in the access of relevant and current information for teaching, learning and research development. Online information resources have the potentials of allowing institutions and researchers to share their own research output with the global community. Online information resources are capable of enhancing research and also lifelong learning through establishing constant and continuous access to shared online archival collections and also providing access to Online Electronic Thesis and Dissertations (ETDs) for the global community. 


\section{Information Search And Access}

The challenge for education in the twenty-first century is to prepare students to use information in their work places, in their personal lives, and as responsible citizens. This is clearly stated in the Report of the ALA Presidential Committee on information literacy as in below:

"Such a restructuring of the learning process will not only enhance the critical thinking skills of students, but will also empower them for lifelong learning and the effective performance of professional and civic responsibilities."

Education is changing from the assembly-line environment of the industrial age offered by textbook teaching to data-rich environment of the information age offered by resource-based learning. In response to this change, information centres have to design new means by which users can maximize the use of these resources with the purpose of gaining access to the information therein. In searching for information, basically six processes are involved as suggested by Kulhthau (2004). These processes are as follows:

Information access on the other hand, boarders around ensuring that information users, have the opportunity to get and use information.

There should be ease of access to information by users regardless of their location, position or status. Lombardi (2000) posited that access, is paramount on users mind. With the advent of technology which further gave birth to the Internet, it has been known for its richness in terms of its information content. It has promoted learning and allowed universal access to information, itallows students to broaden their academic horizon, access information, and also communicate with others on the basis of academics. The Internet gives access to educational databases and also sites that could make a user to be deviant and perverse as the case may be. Also the Internet can

give access to digitized and uploaded research works and holdings of a university. From the above therefore, it is pertinent to note that the accessibility of information provides literacy skills to the recipient, offers acquisition of livelihood skills and assists the information seeker to make informed decision when need be, thereby making the right choice.

\section{Entry Points In An Online Environment}

The following point enables users of the Internet gain access to the resources it contains:

- The Uniform Resource Locator (URL)

- Search Engines e.g. Google, Alta Vista, Ask jeeves, Babylon. Etc

- Online Databases e.g. JSTOR, Library Philosophy, AGORA, LanTEEAL,

- Institutional Repositories e.g. Dspace, Greenstone etc

- Library websites e.g. portal.abu.edu.ng/library

- Library Online Public Access Catalog

IX. Impact Of The Internet On Higher Education Information Seeking

The Internet has tremendous influence on the information seeking behavior of students and academics today. It is justifiable to say that the Internet single-handedly revolutionized campus computing. It did not take long before students were among the largest user segment of this medium. Niederlander (n.d:n.p) posits that the Internet has had a definite impact on how people seek information and their expectations of how the Internet can meet their information needs. Lawrence and Miller (2000) observed that vendors of electronic commerce vigorously promote the idea that the answers to all of our questions are only a keystroke away. Observing the situation at Ahmadu Bello University and judging by the extent of web usage, these observations are spot on, although some would still argue that not everything is available online. It is entirely conceivable why searching for information on the Internet has become popular in higher learning today - by connecting to the Internet an entirely new world of electronic communication and information (with a greater range of topics than any other information source) is opened to students, staff and researchers. Moreover, the wide range of information available online now means that many information queries can be answered from online sources in far lesser time than with traditional, paper-based sources. Speed or instant information/feedback is a driving factor in the ballooning interest in Web information seeking in education.

Mioduser (2000) suggests that the reason behind the Internet's popularity in education is in its most obvious feature: it is a huge repository of hyperlinked knowledge, information, and knowledge manipulation functions (e.g. generation, transmission, storage, processing and retrieval of information), which are at the heart of educational transactions. Mioduser (2000) supposes that the ability to contribute to or to access online libraries, databases, e-journals. museums, and other public information containers on the Internet to satisfy valuable educational functions also appeals to higher education users. 


\section{The Role Of The Library On The Educational Advancement Of Academics.}

Libraries have been the chief conservers of knowledge achieved by men in their intellectual pursuits that helps in generating new ideas and discoveries, while 'education' is an art of making available to each generation the organized knowledge of the past. Louis and Tauber(2010) have rightly opined that "the process of social change are inter-woven in the facts, ideas, and interventions of man ; and each new idea or invention grows out of accumulated and conserved knowledge". 'Education' and 'library' are two inseparable -indivisible concepts, both being fundamentally and synchronically related to and co-existent with each other. One cannot be separated from the other, and the existence of one is impossible without the other. None of them is an end in itself, rather both of them together are a means to an ultimate end. One dies as soon as the other perishes. One survives as long as the other exists. This inter-relation, co-existence, and dependence of one upon the other have been coming down from the birth of human civilization to the posterity through a process of evolution in harmony with varied needs, changes, and circumstances of various stages of human life. Education is an 'aggregate of all the processes by means of which a person develops abilities, altitudes, and other forms of behavior, positive value in the society in which he lives.' Good (2011) succinctly puts it that, it is a 'social process by which people are subjected to the influence of a selected and controlled environment (especially that of the school) so that they may attain social competence and optimum individual development. Education is thus the result of acquired knowledge and the cumulation of observations and experiences, while a library is both the fountain and source, and the protector and storehouse of that knowledge and experience.

Education cannot exist alone in the absence of library, and library has no meaning if it cannot impart education. Education is an eye-opener to a human being ;it gives him perfect, adequate knowledge, creates civic and rational sense, withdraws him from the subjection of low habits, selfish passions, and ignoble pursuits, and thus educes him from abysmal darkness to limpid and perspicuous enlightenment, while library is an instrument of self-education, a means of knowledge and factual information, a centre of intellectual recreation, and a beacon of enlightenment that provides accumulated - preserved knowledge of civilization which consequently enriches one's mental vision, and dignifies his habit, behaviour, character, taste, attitude, conduct, and outlook on life. Library makes available all the records of knowledge of the past and 'present, whereas a man acquires that conserved knowledge to choose between good and bad, the right and wrong, which distinguishes him from the other animals who have no rational power or thinking. A good-well-equipped library is a sine qua non for the intellectual, moral, and spiritual advancement and elevation of the people of a community. It is an indispensable element of the absolute well-being of the citizens and that of the nation at large.

People acquire education through certain institutions, schools, agencies, welfare bodies, museums, and organizations, and library is the most outstanding of such institutions. The utility of a library in education can at once be felt and generalized particularly when one looks into the educational conditions of the poor. The most flagrant aspect of the predicament of the poor people in Nigeria is that their children are subjected to woefully inefficient public education. The degree of reading retardation among the people throughout the nation is traumatically alarming. This is due to their poverty that culminates in their inability to purchase valuable books and also to bear heavy expenses of tuition fees, etc. With the help of the libraries we may very well lodge a "war" or campaign against this poverty for which education has remained handicapped and limited to the people of the upper strata of the society. Libraries make available all the relevant books and other materials almost free of cost, and the children of the poor and the rich alike can derive equal amount of advantages out of this free service that helps in pursuing constructive education. Thus it is pertinent to say that libraries have an essential and close bearing upon the advancement of education and learning at all levels for all the times.

\section{Conclusion}

Students in tertiary institutions of learning need information for their academic activities, this is a fact that cannot be taken for granted. It is important to note also that students/ users must possess the requisite skills necessary to access online information resources. A well articulated and sustained effort is required to provide ICT facilities in these institutions, making them more accessible to students for use. It is now a known fact that the Internet has facilities that supports the teaching and learning processes in institutions. This paper has examined some information seeking models and the role they play in ensuring a better search process by users to achieve maximum results for a sustainable education also ensuring quality in selecting information resources online. Finally this paper provides insights for librarians to help them enhance the users' search experience in the information age.

\section{Recommendations}

1 Computer skills of students should be improved. ICT literacy skills should be incorporated into academic curriculum both at undergraduate and postgraduate levels.

2 Librarians should be equipped with the requisite e-resource searching and retrieval skills to meet up with current trends in their profession. 
3 Academic libraries in the country should have a unified networked information system and also go into consortium to provide more relevant access to local and international contents.

4 Libraries in academic institutions should device a new means of reaching out and creating awareness of eresources and services in order to ensure maximum usage on the part of users. The use of e-mail alerts, text messages social media (facebook and twitter) can be employed.

5 Government should ensure adequate funding of academic institutions.

6 Epileptic electricity supply and poor telecommunication infrastructure should be addressed by government.

\section{References}

[1] Aguolu, C.C. (1984). The Future of Library and Information Services in Nigeria. Nigerian Libraries Vol. 20 p 58.

[2] American Library Association Presidential Committee on Information Literacy: Final Report. (Chicago: American Library Association, 2010). Thoughtful summary of the deliberations of leaders in education and librarianship on the importance of Information Literacy to individuals, business and citizenship with recommendations for implementing the information age school.

[3] Belkin, N.J. Oddu, R. and Brooks, H. (1982). Information Retrieval: Pt 1 Background Theory. Journal of Documentation 8(2) 61 -71.

[4] Brophy, P. (1993). "Network in British Academic Libraries" British Journal of Academic Librarianship, Vol. 8 No. 1:49-60

[5] Case, D.O. (2002). Looking for Information: A Survey Research on Information Seeking, Needs, and Behaviour Amsterdam. Academic Press.

[6] Dadzie, P.S. (2009). "Electronic resources: access and usage at Ashesi University College". $\begin{array}{lllll}\text { Campus-Wideinformation } & \text { systems. Vol. } 22 . & \text { No. }\end{array}$

[7] http://www.emeraldinsight.com/insight/viewcontentservlet?filename=Published/Emeraldfull textarticle/articles/1650220504.ht

[8] Dervin, B. \& Nilan (1986). Information Needs and Users. Annual Review of Information Science and Technology, 22:3-33. Knowledge Industry Publication Inc. New York.

[9] Fourie, I. (2006). Learning from Web Information Seeking Studies: Some suggestions for library and information science practitioners. The electronic library, 24(1), 20-37. Retrieved from

[10] www.emeraldinsi,ght.com/0264-0473.htm.

[11] Gbaje, S.E. (2007). Implementing a National Virtual Library for Higher Institutions in Nigeria. Retrieved from www.sharondeli.aht.com on 03/04/2012.

[12] Ikoja-Odongo, R. and Ochalla, D.N. (2004). Information Seeking Behaviour of the Informal Sector Entrepreneurs: The Uganda Experience. Libri 54, pp. 54-66.

[13] Ikoja-Odongo, R. and Ochalla, D.N. (2004). Information Seeking Behaviour of Formal Sector Entrepreneurs. The Uganda Experience. Libri Vol. 54 pp 54-66.

[14] Ingwersen, P. (2008). Information and Information Science in context. In J. Olaisen, E. Munch-Petersen, P. Wilson (eds.). information Science. From the development of the discipline to social interaction. Oslo: Scandinavian University Press pp 69-111.

[15] Kakai, M.,, Ikoja-Odongo. R. and Kigongo-Bukeny, I.M.N. (2004). A Study of the Information Seeking Behaviour of Undergraduate Students of Makerere University Uganda, World Libraries 14(1), 544-564.

[16] Kari, J. \& Savolainen, R. (2001). Web Searching in the Context of Information Seeking in Everyday Life: The cases of civic and spiritual action. A Research Proposal. Retrieved from http://www.uta.fi/csjakar/kari-savolainen.pdf.

[17] Krikelas, J. (1983). Information Seeking Behaviour: Patterns and Concepts. Drexel Library Quarterly, 19,5-20.

[18] Kuhlthau, C. (2004). Seeking Meaning: a process approach to library and information services. London: Libraries Unlimited ISBN 159158-094-3

[19] Kulthau, C.C. (1993). Seeking Meaning, a Process Approach to Library and Information Services. Norwood, N.J. Ablex, Publishing.

[20] Majid, S., Aozova, A.F. (1999). " Computer literacy and use of electronic sources by academics: a case study of international Islamic University of Malaysia, Asian libraries". Vol. 8, No. 4. 100-111. http://www.emeraldinsight.com/insight/viewcontentservlet? Filename=published/EmeraldFullTextArticle/Articles/1 730080401.html. accessed $\left(8^{\text {th }}\right.$ December, 2011)

[21] Reitz, J.M. (2004). Dictionary of Library and Information Science and Technology. Boston Academic.

[22] Reitze, J.M. (2004). Dictionary of Library and Information Science and Technology. Boston Academy.

[23] Shuling, W. (2007). "Investigation and analysis of current use of electronic resources in University libraries". Library Management. Vol, 28 No. 1 / 2 72-88. http://www.emeraldinsight.com/insight/viewcontentservlet?

[24] Filename=published/EmeraldFullTextArticle/Articles/0150280107.html. accessed $\quad\left(13^{\text {th }}\right.$ January, 2012)

[25] Swain, D.K, and Panda, K.C. (2009). "Use of electronic resources in business school libraries of an Indian: A study of librarians' opinion", The electronic library, Vol. 27, No. 1, pp 74-85.

[26] Taylor, R.S. (1991). Information Use Environment.: In Brenda, Dervin \& Melvin J. Voigt (Eds). Progress in Communication Sciences, Norwood, NJ: Ablex 10.

[27] Weiler. A. (2005). Information-Seeking Behaviour in Generation 4 Students: Motivation, Critical Thinking and Learning Theory (Electronic Version). Journal of Academic Librarianship, 31, 3-15. Wilson T. D. (1999). Models in Information Behaviour Research. Journal of Documentation, Page 249-270. Retrieved from http://www.information.net on 06/03/2012.

[28] Wilson T.D. (1981). On User Studies and Information Needs. Journal of Librarianship. Vol. 37, 3-15. Retrieved from http://www.information.net/tdw/pub/papers/1981 infoneeds.html.

[29] Wilson, T.D. (1997a). Information Beahviour. An Interdisciplinary Perspective. In P. Vakkari,

[30] R. Savolainen \& B. Derkin (Eds). Information Seeking in Context of Proceedings of an International Conference on Research in Information Needs, Seeking and Use in Different Contexts 14-15, August, 1996. Tampere, Findland. London Taylor Graham.

[31] Wilson, T.D. (1999). Models in Information Behaviour Research. Journal of Documentation (Electronic Version) 55,249-270. 